\title{
PENGEMBANGAN KAMUS SAKU ARAB-INDONESIA UNTUK MENINGKATKAN KETRAMPILAN MEMBACA SISWA KELAS VIII DIPESANTREN ROUDHOTUL QUR'AN AN-NOER
}

\author{
Rina Dian Rahmawati*1 \\ Pendidikan Bahasa Arab \\ Universitas KH. A. Wahab Hasbullah \\ Email: rinadianrahmawati@unwaha.ac.id \\ Ima Liana ${ }^{2}$ \\ Pendidikan Bahasa Arab \\ Universitas KH. A. Wahab Hasbullah \\ Email: Imaliana1927@gmail.com
}

\begin{abstract}
The purpose of this study is to develop an Arabic-Indonesian pocket dictionary to improve reading vocabulary and to determine the feasibility and effectiveness of learning media in the form of a pocket dictionary. This research is an $R \mathcal{E} D$ research that adopts the development of ADDIE. The subjects in this study were class VIII students of the Roudhotul Qur'an An-noer Islamic Boarding School, totaling 15 students and data collection used in the form of media expert questionnaires, material expert questionnaires, student response questionnaires, pretest, and post-test. The types of data analyzed produce qualitative and quantitative data with assessment categories to determine product feasibility. The results of this study are: 1) a learning media in the form of an Arabic-Indonesian pocket dictionary has been developed. 2) the feasibility of the pocket dictionary learning media that has been developed is very feasible with an almost comprehensive score reaching a value of 4 (quite valid) based on the assessment of material experts and a very decent score almost completely reaching a value of 4 (quite valid) based on the assessment of media experts. 3) the effectiveness of learning media in the form of pocket dictionaries is very effective, seen from the average pre-test score obtained by students compared to the post-test score, with an average pre-test score of 49 and an average post-test score of 80 .
\end{abstract}

Keywords: Pocket Dictionary Development, Reading Skills, Arabic

\begin{abstract}
Abstrak
Tujuan dari penelitian ini adalah untuk mengembangkan kamus saku Arab-Indonesia untuk meningkatkan kebendaharaan membaca dan untuk mengetahui kelayakan dan
\end{abstract}




\section{Rina Dian Rahmawati, Ima Liana.}

keefektivitasan media pembelajaran berupa kamus saku. Penelitian ini merupakan penelitianan R\&D yang mengadopsi pengembangan dari ADDIE. Subjek dalam penelitian ini adalah peserta didik kelas VIII Pesantren Roudhotul Qur'an An-noer yang berjumlah 15 siswa dan pengumpulan data yang digunakan berupa angket ahli media, angket ahli materi, angket respon siswa, pre test, dan post test. Adapun jenis data yang dianalisis menghasilkan data kualitatif dan kuantitatif dengan kategori penilaian untuk menentukan kelayakan produk. Hasil penelitian ini adalah : 1) telah dikembangkan media pembelajaran berupa kamus saku ArabIndonesia. 2) kelayakan media pembelajaran kamus saku yang telah dikembangkan adalah sangat layak dengan skor hampir menyeluruh mencapai nilai 4 (cukup valid) berdasarkan penilaian ahli materi dan skor sangat layak hampir menyeluruh mencapai nilai 4 (cukup valid) berdasarkan penilaian ahli media. 3) keefektivan media pembelajaran berupa kamus saku adalah sangat efektiv dilihat dari rata-rata skor hasil pre test yang diperoleh siswa dibandingkan dengan skor post test, dengan rata-rata nilai pre test 49 dan rata-rata nilai post test 80 .

Kata kunci: Pengembangan Kamus Saku, Ketrampilan Membaca, Bahasa Arab

\section{A. PENDAHULUAN}

Bahasa arab pertama kali diajarkan dengan tujuan untuk memenuhi kebutuhan seorang muslim dalam menunaikan ibadah, khususnya sholat. Dan seiring berjalannya waktu bahasa arab dipelajari sebagai media untuk komunikasi dan memperoleh informasi. ${ }^{1}$

Keberadaan Bahasa Arab sangat penting di era modern ini, tidak hanya membutuhkan satu aspek pembelajaran Bahasa Arab, tetapi juga beberapa aspek, antara lain menyimak, berbicara, membaca dan menulis (istima', kalam, qiroah, dan kitabah). ${ }^{2}$

\footnotetext{
${ }^{1}$ H.R. Taufiqurrohman, Leksikologi Bahasa Arab, (Malang: UIN Malang Pres, 2008), hal 132

${ }^{2}$ Nurul Huda dan Nabilah Ulfah, Pengembangan Kamus Arab-Indonesia Sebgai Penunjang Pengunaan Baku Ajar Madrasah Tsanawiyah Kelas VIII, Jurnal Alfazuna: 2019
} 
Kamus sebagai media pembelajaran Bahasa Arab dapat memberikan nuansa belajar yang menarik. Pembelajaran Bahasa Arab dengan kamus saku dapat dilakukan di dalam kelas mau pun diluar kelas. Untuk itu diperlukan media yang memudahkan dan menumbuhkan minat baca siswa.

Secara etimologi kamus berasal dari bahasa arab yaitu qaamus. Menurut C.L. Barnhart dalam buku karangan H.R. Taufiqurrahman, kamus adalah "sebuah buku yang memuat kosakata pilihan yang umumnya disusun berdasarkan urutan alphabet dengan disertai penjelasan maknanya dan dilengkapi informasi lain yang berhubungan dengan kosakata". ${ }^{3}$

Dalam konteks pembelajaran bahasa Arab, membaca memiliki urgensi tersendiri, yaitu :1)Membaca merupakan kunci untuk membuka khazanah pengetahuan kebudayaan Islam2)Long life tidak akan terwujud Kalau yang melakukannya tidak dapat membaca3)Memahami khazanah intelektual klasik dan moderen.

a. Karakteristik Membaca

Karakteristik membaca tidak jauh beda dengan pembelajaran bahasa ibu, yaitu :

1) Kegiatan pembelajaran berbasis pada pemahaman isi bacaan dengan didahului oleh pengenalan kosa kata kemudian membahas isinyasecara bersamaan Denman Bastian dozen.

${ }^{3}$ Nurul Huda, Pengembangan Kamus Arab-Indonesia 


\section{Rina Dian Rahmawati, Ima Liana.}

2) Tata Bahasa tidak dibahas secara Panjang lebar, namun dipilih yang sesuai Denman fungi maknanya semata.

3) Kegiatan pembelajaran dilanjutkan dengan hadirnya tugas-tugas yang dijawab oleh mahasiswa untuk mengokohkan pemahaman akan bahasa bacaan yang dimaksud.

4) Membaca diam lebih utama dari pada membaca keras.

5) Tujuan utamanya agar mahasiswa mampu memahami teks ilmiah untuk keperluan studi mereka.

6) Materi pembelajaran berupa buku bacaan utama dengan suplemen bacaan panjang untuk perluas.4

b. Hakikat membaca

Menurut Syafi'ie hakikat membaca yaitu : Pengembangan ketrampilan, mengamati dan memahami kata-kata yang terdapat pada tulisan, Proses berfikir, Mengolah informasi, Kegiatan visual, Menghubungkan tulisan dan bunyi yang sesuai, Memahami makna terhadap tulisan. ${ }^{5}$

c. Tujuan membaca

\footnotetext{
${ }^{4}$ Sri Dahlia, "Urgensi metode qiraah dalam pembelajaran bahasa arab di PTAI", 2013 hal 20

${ }^{5}$ Dahlia Patiung, "Membaca sebagai sumber pengembangan intelektual", Al-Daulah, Vol.5, No. 2, Desember 2016, 354-355
} 
Membaca memiliki tujuan utama yaitu memahami suatu bacaan yang terdapat dalam teks, yang akan menghasilkan sebuah informasi sehingga bisa menjadi bekal pengetahuan untuk masa depan. ${ }^{6}$

Dalam bukunya Muhammad Asdam menjelaskan tujuan membaca menurut Puji Santoso yaitu :

1) Menikmati keindahan yang terdapat dalam bacaan

2) Membaca bersuara agar pembaca dapat menikmati teks bacaan

3) Untuk memahami suatu bacaan menggunakan strategi

4) Mencari penggetahuan tentang suatu topik

5) Menghubungkan pengetahuan baru dengan schemata seseorang

6) Mencari informasi untuk menyusun bacaan atau laporan

7) Diberi kesempatan untuk melakukan ekspektasi untuk meneliti sesuatu yang terdapat pada bacaan

8) Menjawab pertanyaan yang dijabarkan dalam bacaan. ${ }^{7}$

Ketrampilan membaca memegang peran yang sangat penting dalam kehidupan manusia, karena membaca akan memperoleh berbagai wawasan dan informasi baru. Oleh karena itu apabila siswa tidak memiliki kemauan untuk membaca maka siswa akan kesulitan dalam melaksanakan kegiatan pembelajaran.Siswa kelas VIII pondok pesantren putri roudlotul qur'an an-noer Jagalan Jombang masih belum memiliki wadah khusus untuk mempelajari bahasa

\footnotetext{
${ }^{6}$ Muhammad Asdam, Bahasa Indonesia (pengantar pengembangan kepribadian dan intelektual), (makassar : LIPA, 2016), 141

${ }^{7}$ Dahlia Patiung, membaca sebagai, 356
} 


\section{Rina Dian Rahmawati, Ima Liana.}

arab maka siswa dipondok tersebut kesusahan dalam menyelesaikan permasalahan pelajaran bahasa arab terutama dalam ketrampilan membaca. Masalah yang sering ditemukan santri ketika membaca teks arab seperti membaca Al-Qur'an, dan masih ada juga yang menggunakan bahasa ibu (bahasa daerah). Disamping itu santri kelas VIII pondok pesantren roudlotul qu'an an-noer juga masih banyak yang merasa kurang percaya diri dan takut akan salah dalam membaca teks arab dan menyimpulkan isi bacaan.

Berdasarkan masalah diatas maka penulis merasa dibutuhkan pengembangan sebuah kamus saku yang disusun berdasarkan kebutuhan siswa yang mengacu pada buku pegangan siswa Bahasa Arab kelas VIII.

\section{B. METODE PENELITIAN}

Model pengembangan ini menggunakan jenis penelitian pengembangan research and development. Menurut sugiyono dalam buku yang berjudul metode penelitian dan pengembangan (R\&D) adalah metode penelitian yang digunakan untuk menghasilkan produk tertentu, dan menguji keefektifan produk tersebut. ${ }^{8}$

Richey dan Klein mendefenisikan penelitian pengembangan the systematic study, development, and evaluation with the aim of establishing an empirical basis for the

\footnotetext{
${ }^{8}$ Sugiyono, Metode Penelitian Pendidikan, Pendekatan Kuantitatif, Kuantitatif, dan R\&D,(Bandung: Alfabeta, 2012), hal 297
} 
creation of instructional products and tools and new or enhanced models that govern their development. ${ }^{9}$

Dalam penelitian dengan metode $\mathrm{R} \& \mathrm{D}$, tahap awal yang dilakukan adalah penelitian pendahuluan. Penelitian ini bertujuan untuk mengumpulkan informasi kemudian dikumpulkan dan dianalisis untuk bahan pertimbangan dalam pengembangan yang mampu memecahkan masalah yang dihadapi. 10

Model pengembangan yang digunakanDalampengembanganini adalah model ADDIE. Model ini terdiri atas lima langkah, yaitu :

1. Tahap Analisis

Pada tahap analisis kegiatan yang dilakukan antara lain :

a. Menganalisis kompetensi yang harus dikuasai oleh siswa.

b. Menganalisis karakteristik siswa berkenaan dengan pengetahuan, sikap, dan ketrampilan yang dimiliki siswa

c. Menganalisis materi yang relevan untuk pencapaian kompetensi yang diinginkan dimiliki para siswa.

2. Tahap Perancangan (Desain)

Tahap perancangan fokus pada pemilihan materi sesai dengan karakteristik siswa dan tuntutan kompetensi yang ingin dicapai, strategi

\footnotetext{
${ }^{9}$ Richey and Klein, Design And Development Research, Methods, Strategies, and Issues, (New Jersey: Mahwah, 227), hal 01

${ }^{10}$ Dr. Iks Prasetya, Teknik Analisis Data dalam Research And Development
} 


\section{Rina Dian Rahmawati, Ima Liana.}

pembelajaran, bentuk dan metode asesmen serta evaluasi. Dalam tahap ini struktur buku ajar dan kerangka isi buku ajar dirancang.

\section{Tahap Pengembangan}

Pada tahap Pengembangan dilakukan beberapa kegiatan, antara lain : pencarian dan pengumpulan sumber yang relevan, pembuatan gambaran ilustrasi, bagan, pengetikan, pengeditan, serta pengaturan lay out buku ajar. Kegiatan berikut adalah kegiatan memvalidasi produk pengembangan dan revisi sesuai masukan para ahli.

4. Tahap Implementasi

Pada tahap ini hasil pengembangan diterapkan dalam pembelajaran untuk mengetahui pengaruhnya terhadap kualitas pembelajaran yang meliputi keefektifan, kemenarikan, dan efisiensi pembelajaran. Penerapan dilakukan pada kelompok kecil untuk mendapatkan masukan dari siswa dan guru sebagai bahan perbaikan produk.

5. Tahap Evaluasi

Tahap terakhir adalah tahap evaluasi yang meliputi evaluasi formatif dan evaluasi sumatif. Dalam penelitian ini hanya dilakukan evaluasi formatif, karena jenis evaluasi ini berhubungan dengan tahapan penelitian pengembangan untuk memperbaiki produk pengembangan yang dihasilkan. ${ }^{11}$

\section{HASIL PENELITIAN}

\footnotetext{
${ }^{11}$ Made Tegeh, Nyoman Jampel, Ketuat Putdjawen, Pengembangan buku ajar model penelitian pengembangan dengan model ADDIE, (jurusan teknologi pendidikan FIP Undiksha,2015), hlm210
} 


\section{Desain Produk}

Penulis memulai menyusun kamus saku menggunakan photoshop. Berikut adalah gambar cover depan dan belakang, dan isi kamus.

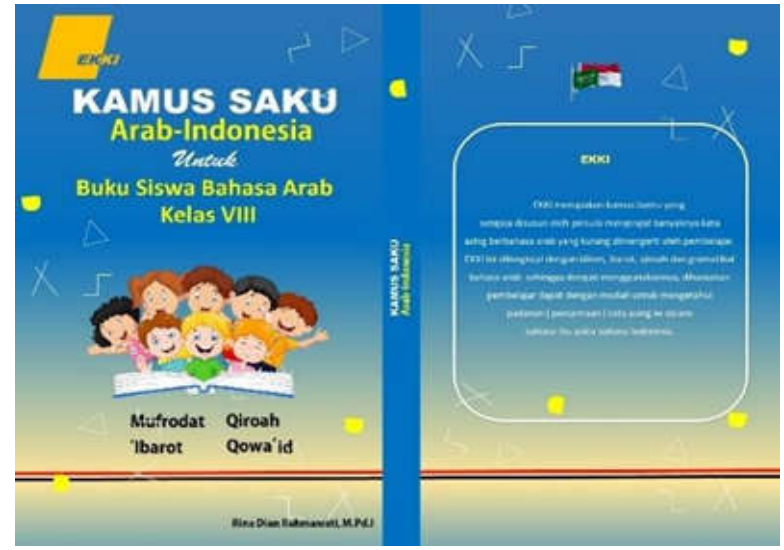

Cover pada kamus ini menggunakan font KBJelybean pada tulisan "Kamus Saku" dengan ukuran font 60 pt, pada tulisan "Arab-Indonesia" menggunakan font SquareKids dengan ukuran 60 pt, dan font Kbbubblegum pada tulisan "Buku Siswa Bahasa Arab Kelas VIII" dengan ukuran font 24 pt.
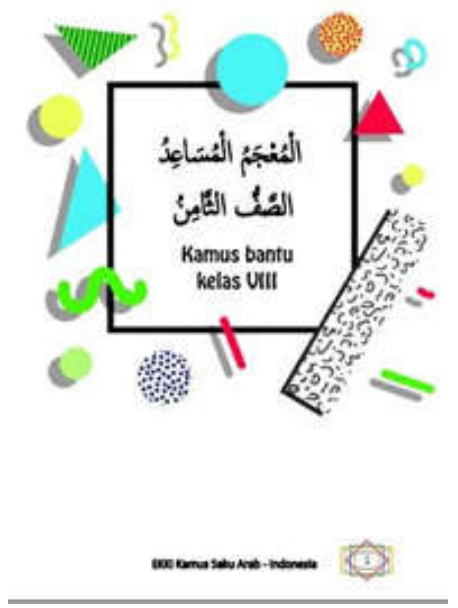


\section{Rina Dian Rahmawati, Ima Liana.}

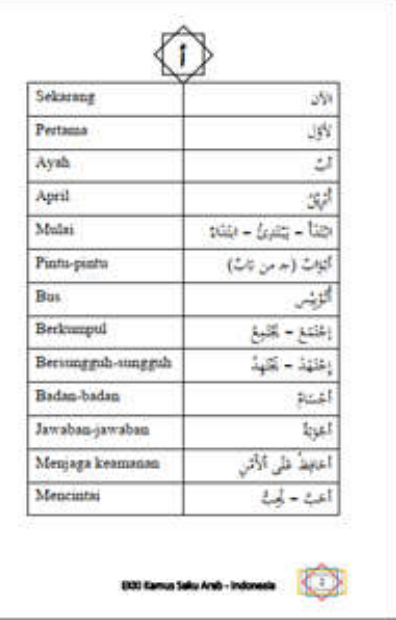

Isi kamus menggunakan font Times News Roman yang digunakan pada kata pengantar, petunjuk penggunaan kamus, daftar isi, dan pada arti Indonesia, sedangkan font ArabicTypesetting digunakan pada tulisan Arab ditetap bab, dan font TraditionalArabic digunakan pada tulisan Arab isi kamus dan masingmasing font, font Arab disetiap bab berukuran 28 PT, font Indonesia disetiap bab $12 \mathrm{pt}$.

\section{Validasi dan Revisi produk}

Setelah penyusunan kamus saku selesai, maka dilakukan uji validasi kepada ahli materi dan ahli desain yaitu Dosen Pendidikan Bahasa Arab UNWAHA untuk mengetahui tingkat keefektifan media dalam penggunaan pada proses pembelajaran. Validasi media pembelajaran ini berbentuk data kuantitatif dan kualitatif.

a. Penilaian ahli materi 
Berdasarkan perhitungan angket validasi maka pengamatan yang dilakukan oleh ahli materi hampir menyeluruh mencapai nilai 4. Maka nilai pencapaian ini termasuk dalam kriteria cukup valid atau sebagian revisi.

Ahli materi juga memberikan saran dan masukan terhadap kamus saku tersebut, diantaranya adalah : 1) Untuk sampul barangkali bisa didesain dengan warna yang menarik minat untuk siswa/i MTs 2) Materi dipercantik dengan warna tampilanyang menarik minat baca.

b. Penilaian ahli media

Berdasarkan perhitungan diatas maka pengamatan yang dilakukan oleh ahli desain hampir keseluruhan mencapai nilai 4. Maka nilai pencapaian ini termasuk dalam kriteria cukup valid atau sebagian revisi.

Ahli media juga memberikan saran dan kritik, sebagai berikut : 1) Pada qiroah tidak perlu dicantumkan tulisan bacaannya hanya perlu ditulis judul dan halaman bukunya 2) Nama buku belum jelas perjelas dengan buku yang diteliti.

\section{Uji Coba Pemakaian}

Penelitian ini dilakukan di Pondok Pesantren Roudhotul Qura' an AnNoer, subjek penelitian ini adalah siswa kelas VIII tahun akademik 2020/2021yang bertempat tinggal di Pondok Pesantren Roudhotul Qura' an AnNoer.

Berikut penjelasan data pre test dan post test dari santri kelas VIII pada uji coba lapangan sebagai berikut : 


\section{Rina Dian Rahmawati, Ima Liana.}

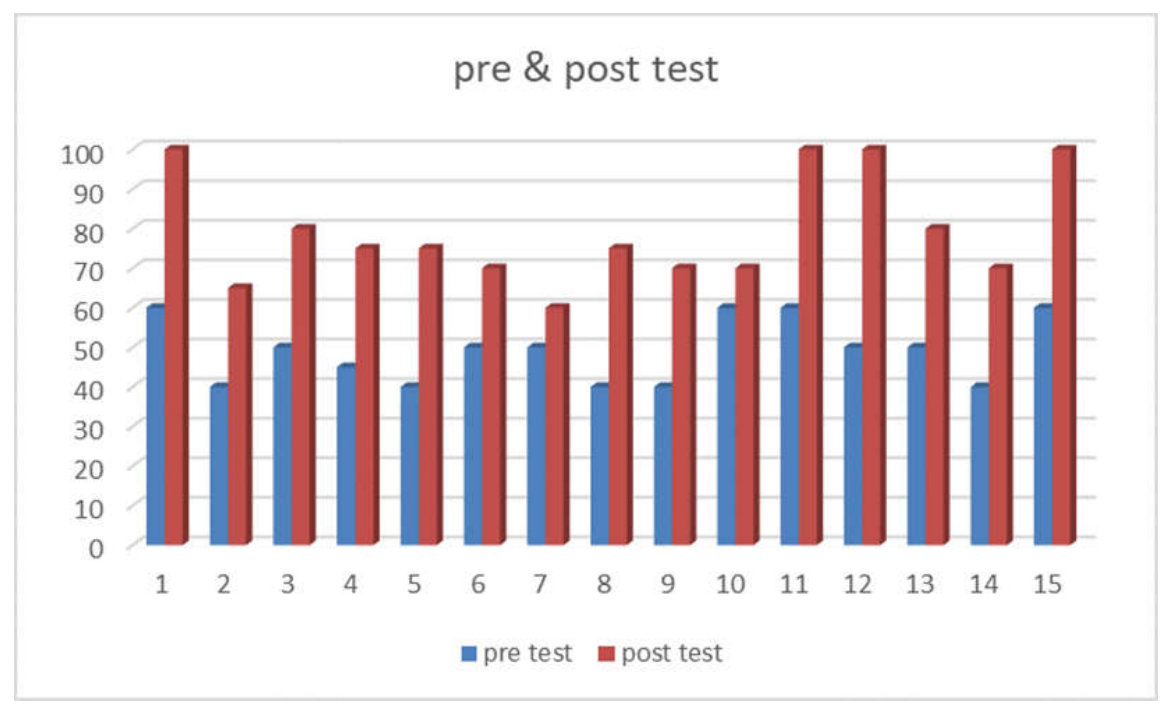

Berdasarkan data diagram diatas menunjukan bahwa rata-rata nilai pre test adalah 49 dan rata-rata nilai post test 80 . Maka nilai post tes menunjukan lebih bagus dari nilai pre test. Dan dapat disimpulkan bahwa media kamus saku Arab-Indonesia ini efektif digunakan dan dapat meningkatkan kemampuan membaca santri Pondok Pesantren Roudhotul Quran An-Noer.

\section{KESIMPULAN}

Pengembangan media kamus saku Arab-Indonesia ini dibuat menggunakan photoshop. Setelah pembuatan kamus selesai maka kamus divalidasi oleh ahli media dan ahli materi. Dan hasil dari validasi ahli materi dan ahli media sama-sama mendapatkan skor 4 yang artinya masuk dalam kategori sangat valid. Efektivitas media pembelajaran Kamus Saku Arab-Indonesia dapat dilihat dari perbedaan nilai pre test dengan perolehan rata-rata 49 dan nilai pre test dengan perolehan rata-rata 80 . Dari pemerolehan rata-rata pre test dapat disimpulkan bahwa kamus saku Arab-Indonesia efektif digunakan dan dapan 
meningkatkan kemampuan belajar santri Pondok Pesantren Roudhotul Quran An-Noer.

\section{E. DAFTAR PUSTAKA}

Asdam, Muhammad, Bahasa Indonesia (pengantar pengembangan kepribadian dan intelektual), (makassar : LIPA, 2016)

Dahlia, Sri. (2013). Urgensi Metode Qiraah Dalam Pembelajaraan Bahasa Arab di PTAI.

Huda, Nurul dan Nabilah Ultah. (2019). Pengembangan Kamus Arab-Indonesia Sebagai Penunjang Penggunaan Buku Ajar Madrasah Tsanawiyah Kelas VIII. Jurnal Alfazuna.

Prasetya, Iks. Teknik Analisis Data dalam Research And Development.

Patiung, Dahlia, "Membaca sebagai sumber pengembangan intelektual", Al-Daulah, Vol.5, No. 2, Desember 2016.

Richey and Klien. Design And Development Research, Methods, Strategies, and Issues, (New Jersey: Mahwah).

Sugiyono. (2012). Metode Penelitian Pendidikan, Pendekatan Kuantitatif, Kualitatif, dan RED. Bandung.

Taufiqurrohman, H. R (2008). Leksikologi Bahasa Arab, UIN Malang, Malang. Tegeh, Made, Nyoman Jampel, Ketut Putdjawen. (2015). Pengembangan Buku Ajar Model Penelitian Pengembangan Dengan Model ADDIE. Jurusan teknologi pendidikan FIP Undiksha. 


\section{Rina Dian Rahmawati, Ima Liana.}

